\title{
Properties of Edible Films Based on Oxidized Starch and Zein
}

\author{
Elizabeth Argüello-García, Javier Solorza-Feria, J. Rodolfo Rendón-Villalobos, \\ Francisco Rodríguez-González, Alfredo Jiménez-Pérez, and Emmanuel Flores-Huicochea
}

Instituto Politécnico Nacional, CEPROBI, Calle Ceprobi No. 8, Col. San Isidro, 62730 Yautepec, MOR, Mexico

Correspondence should be addressed to J. Rodolfo Rendón-Villalobos; rrendon@ipn.mx

Received 27 September 2013; Revised 11 December 2013; Accepted 14 December 2013; Published 9 January 2014

Academic Editor: Jan-Chan Huang

Copyright (C) 2014 Elizabeth Argüello-García et al. This is an open access article distributed under the Creative Commons Attribution License, which permits unrestricted use, distribution, and reproduction in any medium, provided the original work is properly cited.

\begin{abstract}
The objective of this work was to investigate the effect of zein and film formulation on mechanical and structural properties of native (FNS), and oxidized with 2.5\% (FOSA) and 3.5\% (FOSB) banana starch. The oxidized starch showed differences from native starch due to the oxidation process, showing a decrease in lipids, proteins, and amylose. The increase of the sodium hypochlorite increased the content of carbonyl and carboxyl groups in the ranges $0.015-0.028 \%$ and $0.022-0.031 \%$, respectively. The film obtained from FOSB displayed the highest tensile strength $(5.05 \mathrm{MPa})$ and satisfactory elongation value $(27.1 \%)$. The zein addition caused a decrease in these mechanical properties, as well as a significant decrease in water vapour permeability (WVP). However, films from FOSA and FOSB showed higher permeability than that of the native starch. The addition of glycerol and the level of oxidation increased the films moisture. Micrographs showed that, during the oxidation process, impurities were largely eliminated from the starch granule, noting more homogeneous structures both in granules and films.
\end{abstract}

\section{Introduction}

There is currently a revival of worldwide interest in the use of biopolymers for applications in which synthetic polymers have traditionally been the materials of choice. Materials of interest include different synthetic or biosynthetic polymers $[1,2]$, as well as plant based polymers such as polysaccharides, starch, and cellulose, which represent the most characteristic family of these natural polymers [3-6]. In the polymer field, interest in starch, a well-known hydrocolloid biopolymer, has been recently renewed due to its abundance, low-cost, biodegradability, and the possibility of processing, using conventional polymer processing equipment [7-9].

Starch is produced from various sources in the form of granules and is mainly isolated from cereal grains such as maize, wheat, rice, and sorghum although tubers such as potato, cassava, sweet potato, and sago are also used, and it can be found in leaves legume seeds and fruits as well. It is composed of amylose, a linear polymer (poly- $\alpha-1,4-\mathrm{D}$ glucopyranoside), which is distributed mostly in the starch granule amorphous domains (lamella), with small amounts in the semicrystalline granule ring and amylopectin (poly$\alpha-1,4$-D-glucopyranoside and $\alpha-1,6-\mathrm{D}$-glucopyranoside), a branched polymer that gives place to the crystalline lamella $[10,11]$. The relative amounts and molar masses of amylose and amylopectin vary with the starch source, yielding materials of different mechanical properties and biodegradability $[12,13]$. Native banana starch has the potential to be a commodity starch because of its specific properties and its potential production from low-cost, cull bananas. Green banana pulp contains up to $70-80 \%$ starch on a dry weight basis, a percentage comparable to that in the endosperm of corn grain and the pulp of white potato [14].

However, the strong hydrophilicity and poor mechanical properties of the materials based on starch prevent its application in the plastic products. As a result, it is logical to chemically modify starch to improve its properties for certain applications. Starch oxidation is an alternative to improve starch properties, this reaction is widely used in many industries, particularly in applications where film formation and adhesion properties are desired [15]. Oxidized 
starch is widely used in industries to provide surface sizing and coating property [16]. Although the main outlets for oxidized starch are in the paper and textile industries, its application in the food industry is increasing because of its low viscosity, high stability, and high transparency, excellent film-forming, and binding properties [16, 17]. Nevertheless, its application as a kind of package material in the food industries, especially as an edible film, offers a large space needed to fulfill. Hydroxyl groups on starch molecules are first oxidized to carbonyl groups and then to carboxyl groups [18]. Therefore, the numbers of carboxyl and carbonyl groups on oxidized starch indicate the level of oxidation and affect its properties [19]. Various natural biodegradable polymers, such as protein and polysaccharides-based edible films, can potentially serve as coating materials for environmentally friendly packing [5]. Food proteins have been widely applied. Corn zein, an alcoholic-soluble protein, has been used as a good renewable and biodegradable material for package film forming, coatings, and plastics applications [20]. It has excellent film forming properties and can be used for fabrication of biodegradable films. Therefore, the most promising application of zein appears to be for biodegradable films and coatings for packaging applications. These films are formed by drying alcoholic aqueous dispersions.

In this study, the aim was to investigate the influence of zein and film formulation (polymer, casting solvent, and additives) on mechanical and structural properties of oxidized banana starch edible films.

\section{Experimental}

2.1. Materials. Commercial hard green (unripe) banana fruits were purchased from the local market in Cuautla, Morelos, Mexico. All commercially available chemical reagents were of reagent grade and used as received without further purification.

2.2. Isolation of Starch. Banana fruits were peeled and cut into $5 \mathrm{~cm}$ slices and immersed immediately in citric acid solution $(0.3 \% \mathrm{w} / \mathrm{v})$ to prevent oxidation of the fruit and macerated (3.6 kg fruit: $6 \mathrm{~L}$ citric acid solution) at low speed for $2 \mathrm{~min}$ in a laboratory blender (L1-3, Inter Instruments, Mexico). The slurry was sieved in an electric sifter (RMU Testing Equipment, Bergamo, Italy) using standard Tyler sieves (W.S. Tyler, Mentor, OH, USA) with mesh numbers 40, 100, 200, 270 , and 325 , washed thoroughly with distilled water until it was clean. Then, the remaining was centrifuged three times in a batch centrifuge (GEA Westfalia Separator Group, Oelde, Germany). The white starch sediments were dried in a spray dryer (GEA Niro, Copenhagen, Denmark), with an inlet temperature of 130 to $150^{\circ} \mathrm{C}$, the solids concentration in the feeding line was $30 \%$ to $40 \%(\mathrm{w} / \mathrm{v})$, and the outlet temperature was 70 to $80^{\circ} \mathrm{C}$. The powder obtained was ground to pass through a US 100 sieve (W.S. Tyler, Mentor, OH, USA) and stored at room temperature in a glass container.
2.3. General Oxidation Procedure. Hypochlorite-oxidized banana starch was prepared according to the method of Y.-J. Wang and L. Wang [19] in alkaline medium:

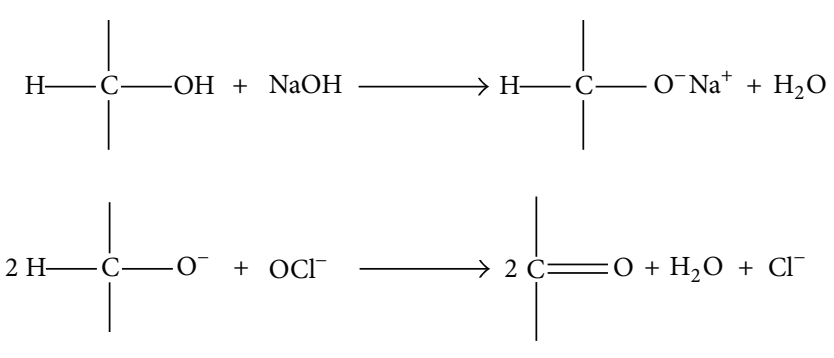

Banana starch slurry containing 35\% (w/w) dry solids was prepared and the $\mathrm{pH}$ was adjusted to 9.5 with $2 \mathrm{~N} \mathrm{NaOH}$ solution. The temperature of the slurry was maintained at $35^{\circ} \mathrm{C}$ and sodium hypochlorite $(2.5 \%$ and $3.5 \%$ active chlorine based on starch; oxidations A and B, resp.) was manually added by dropwise over a period of $30 \mathrm{~min}$ with stirring. During the addition of reagent and the course of reaction, the $\mathrm{pH}$ of the slurry was maintained at 9.5 with $1 \mathrm{~N} \mathrm{NaOH}$ solution. The reaction was terminated by the addition of distilled water and the $\mathrm{pH}$ was adjusted to 7.0 with $1 \mathrm{~N} \mathrm{H}_{2} \mathrm{SO}_{4}$ solution. The sample was thoroughly washed three times with excess distilled water and then dried at $50^{\circ} \mathrm{C}$ for $48 \mathrm{~h}$ in an oven. Finally, dry-milling and sieving (100 mesh) were used to obtain the hypochlorite-oxidized banana starch.

2.4. Starch Content. Total starch content (TSC) was analyzed according to Goñi and Valentín-Gamazo [21]. The sample $(50 \mathrm{mg}$ ) was dispersed in $3 \mathrm{~mL}$ of distilled water and mixed with $3 \mathrm{~mL}$ of $4 \mathrm{M} \mathrm{KOH}$ and the mixture was intensively stirred with a magnetic bar for $30 \mathrm{~min}$ at room temperature. The dispersed sample was then subjected to hydrolysis treatment with amyloglucosidase (14 units/mg of protein) (Roche, Indianapolis, IN, USA) and subsequently incubated $\left(60^{\circ} \mathrm{C}, 45 \mathrm{~min}, \mathrm{pH} 4.75\right)$. Released glucose was assessed using a glucose oxidase/peroxidase assay (Sera-Pak Plus, Bayer, Mexico). Total starch content was calculated as glucose ( $\mathrm{mg}$ ) $\times 0.9$; potato starch was used as a reference. The amylose content of the isolated starches was expressed as the apparent amylose and total amylose content using the method of Hoover and Ratnayake [22].

2.5. Scanning Electron Microscopy (SEM). The granule morphology of starch and edible films samples was observed by JSM-100 scanning electron microscopy (SEM) instrument (JEOL Ltd., Tokyo, Japan) after coating with gold film under vacuum [23].

2.6. Determination of Carbonyl Content. The carbonyl content of the oxidized starches was determined by the procedure of Y.-J. Wang and L. Wang [19]. A dry sample (4 g) was dispersed in distilled water $(100 \mathrm{~mL})$ and the slurry was heated to boiling for $20 \mathrm{~min}$ to make it completely gelatinized. The cooled solution was adjusted to a $\mathrm{pH}$ value of 3.2 with $0.1 \mathrm{M}$ $\mathrm{HCl}$ aqueous solutions, and then $10 \mathrm{~mL}$ of hydroxylamine 
chloride (HMC) was added (HMC, $25 \mathrm{~g} ; 100 \mathrm{~mL} \mathrm{0.5} \mathrm{M} \mathrm{NaOH}$ diluted to $500 \mathrm{~mL}$ ). After this, the sample was placed in a water bath at $40^{\circ} \mathrm{C}$ for $4 \mathrm{~h}$ under constant agitation. The excess $\mathrm{HMC}$ was back-titrated to a $\mathrm{pH}$ value of 3.2 with $0.1 \mathrm{M} \mathrm{HCl}$. A blank test was performed with native starch. All samples were tested three times and the coefficient of variation was $1 \%$. The carbonyl content given by (1) was calculated as

$$
\begin{aligned}
& \% \text { Carbonyl } \\
& =\frac{[(\text { blank }(\mathrm{mL})-\text { sample }(\mathrm{mL})) \times 0.1 \times 0.028]}{\text { sample weight }(\mathrm{g})} \times 100 \text {, }
\end{aligned}
$$

where $0.1=$ molarity of $\mathrm{HCl}$ and $0.028=$ conversion factor from chemical equivalent to grams of carbonyl (28) and conversion from liters to $\mathrm{mL}(1 / 1000)$.

2.7. Determination of Carboxyl Content. The carboxyl content of starch was determined following the Chattopadhyay et al. method [24] with some modifications. Briefly, starch sample $(2 \mathrm{~g})$ was accurately weighed and suspended in $25 \mathrm{~mL}$ of distilled water and transferred to a $500 \mathrm{~mL}$ beaker, and the volume was adjusted to $300 \mathrm{~mL}$ with distilled water. The starch slurry was heated in a boiling water bath with continuous stirring for $15 \mathrm{~min}$ to ensure complete gelatinization. The hot sample was immediately titrated with $0.1 \mathrm{~N} \mathrm{NaOH}$ using phenolphthalein as indicator. A blank determination was run on the original sample in the same manner. The carboxyl content of the sample was calculated using the following relationship:

$$
\begin{aligned}
& \frac{\text { acidity meq. }}{\text { starch }(100 \mathrm{~g})} \\
& =\frac{[(\text { sample }(\mathrm{mL})-\text { blank }(\mathrm{mL})) \times 0.1 \times 100]}{\text { sample weight }(\mathrm{g})}, \\
& \% \text { Carboxyl }=\frac{\text { acidity meq. }}{\text { starch }(100 \mathrm{~g})} \times 0.045,
\end{aligned}
$$

where 0.1 is normality of $\mathrm{NaOH}$ and 0.045 is the conversion factor from meq to grams of carboxyl.

2.8. Preparation of Starch Films. The edible films (EF) were prepared by the casting method, using a defined concentration of native or oxidized banana starch ( $4 \% \mathrm{w} / \mathrm{w}$ dry solids), glycerol ( $2 \% \mathrm{w} / \mathrm{w}$ of starch), and zein ( 1.5 and $0.5 \mathrm{~g}$ were added to $15 \mathrm{~mL}$ ethanol) [25]. The EFs were produced by slowly dispersing starch using glycerol as plasticizer. The suspension was preheated from 30 to $95^{\circ} \mathrm{C}$ for $10 \mathrm{~min}$ in water bath under agitation, to gelatinize starch and homogenize the solution, and then it was cooled down to $65^{\circ} \mathrm{C}$, followed by the addition of zein and making the solution up to a final mass of $100 \mathrm{~g}$ with water. The film-forming suspension was heated up with continuous mixing at $95^{\circ} \mathrm{C}$ for $10 \mathrm{~min}$ in water bath, according to Mali et al. [25]. The mixtures were cast on glass plates (12.7 $\times 3.2 \times 125 \mathrm{~mm}$ ) and dried at $65^{\circ} \mathrm{C}$ for $5 \mathrm{~h}$ in an oven with circulating air. Films were peeled off and conditioned at $25^{\circ} \mathrm{C}$ and $57 \%$ relative humidity $(\mathrm{RH})$.
2.9. Mechanical Analysis. The mechanical properties included the tensile strength (TS) and percent of elongation at break $(\% E)$. Stress-strain mechanical properties of the films were evaluated by using a TA-XT2i Texture Analyzer (Stable Microsystems, Haslernere, UK), equipped with a $25 \mathrm{~kg}$ load cell, according to the conditions set by ASTM 882-09 method [26]. At least five specimens, with a size of $600 \times 10 \mathrm{~mm}$, were cut from each kind of edible films. Before characterization, all film samples were conditioned at $25^{\circ} \mathrm{C}$ and $57 \% \mathrm{RH}$ (a saturated $\mathrm{NaBr}$ solution) relative saturation humidity $(\mathrm{RH})$ for $72 \mathrm{~h}$, and the thickness of the samples was measured with a micrometer (Mitutoyo, Tokyo, Japan) before test. Measurements were taken at ten different positions for each sample and the average value of these determinations was calculated. This average value was used to calculate the cross-sectional area of the samples (the area is equal to the thickness multiplied by the width of each sample). Initial grip separation was $40 \mathrm{~mm}$ and cross-head speed was $5 \mathrm{~mm} / \mathrm{min}$. The tensile strength was calculated by dividing the applied force needed to break a sample, by the cross-sectional area. Percent elongation at break was expressed as percentage of change of the original length of a specimen between grips at break.

2.10. Water Vapor Permeability. The water vapor permeability (WVP) was evaluated using the modified ASTM E 96-95 desiccant method, also known as "the test cell" [27]. Since in a previous work, films permeability did not reach the equilibrium even at 30 days storage [28], and it was decided to do this test at 30 and 60 days after films production. The films were previously equilibrated for at least five days in a desiccator at $57 \% \mathrm{RH}$ using a saturated $\mathrm{NaBr}$ solution. A circular opening with an area of $0.005439 \mathrm{~m}^{2}$ on the permeation cell was covered thoroughly with a film of the same shape and area. Dried silica was placed into the cell, making it almost exempt of moisture (about 0\% RH). An atmosphere of $75 \% \mathrm{RH}$ was obtained with a saturated solution of $\mathrm{NaCl}$ out of the permeation cell. Every hour, the gain in weight was monitored until no further variations were observed. Once the permeation tests were done, the film thicknesses were measured at ten different points using a digital micrometer (Mitutoyo, Tokyo, Japan) and the WVP in $\mathrm{g} \mathrm{Pa}^{-1} \mathrm{~s}^{-1} \mathrm{~m}^{-1}$ was calculated using the following equation:

$$
\mathrm{WVP}=\left[\frac{\mathrm{WVTR}}{S\left(R_{1}-R_{2}\right)}\right] d,
$$

where WVTR is the water vapor transmission rate, calculated from the slope of the straight line $(\mathrm{g} / \mathrm{s})$, obtained from the graphic weight gain (g) versus time (s), and divided by the cell area $\left(\mathrm{m}^{2}\right) . S$ is the saturated water vapor pressure at the test temperature $\left(25^{\circ} \mathrm{C}\right), R_{1}$ is the relative humidity $(\mathrm{RH})$ of the desiccator, $R_{2}$ is the relative humidity of the permeation cell, and $d$ is the film thickness (m).

2.11. Statistical Analysis. One-way analysis of variance at a significance level of $\alpha=0.05$ was applied to the data. In case of significance, the Tukey multiple comparison method was 


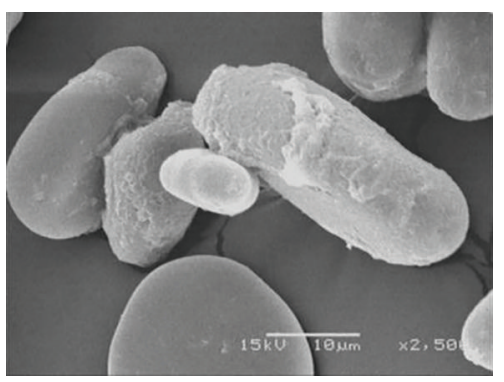

(a)

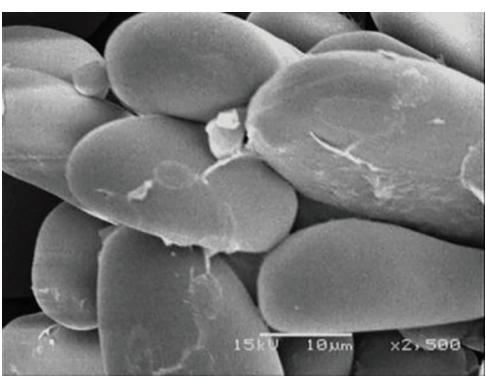

(b)

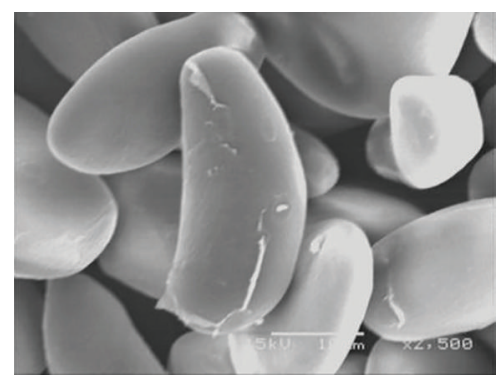

(c)

FIGURE 1: SEM micrographs of granules of banana starch. Native starch (a) oxidized with $2.5 \%$ (b) and $3.5 \%$ (c) active chlorine (scale bar: $10.0 \mu \mathrm{m})$.

applied. The SigmaStat ver. 2.01 (Systat Software Inc., San Jose, Calif., USA) statistical program was used.

\section{Results and Discussion}

3.1. Characterization of Starches. Total starch content for the plantain samples $(87.33 \%)$ was greater than that reported by García-Tejeda et al. [28], of $85.04 \%$ and lower than the one reported by Jiménez-Vera et al. [29] of $96.92 \%$. These slightly different values are probably due to the starch extraction method, since the methodology used in this study was carried out at pilot level. This decrease may also be attributed to the starch hydrolysis and depolymerisation, as well as to the oxidation and subsequent leaching out during native starch modification, of pigments, lipids (which are usually forming complexes with amylose inside the starch granule), and proteins [19]. This, in turn, might result in a decrease in the capacity to form iodine complexes. Kuakpetoon and Wang [30] found that the oxidation reaction led to a decrease of the apparent amylose content from 32.74 to $14.44 \%$, which was due to the mentioned starch depolymerisation, since the small or short chains, produced during the oxidation process, were not able to form complexes with iodine [31].

3.2. Morphological Studies of the Starch. The variation of the shape of starch granules depends on the botanical source, and they are found in the nature in different shapes and sizes [32]. Figure 1 shows the micrographs at a 2500x resolution of NS granules, where it is observed that these have oval and elongated shapes, with an average length of $10 \mu \mathrm{m}$ wide and $40 \mu \mathrm{m}$ length. These lengths were smaller than those reported by García-Tejeda et al. [28], between 13 and $60 \mu \mathrm{m}$. It may be observed that NS (Figure 1(a)) is surrounded by residual cells and presumably bits of proteins and pigments [33].

These impurities were partially eliminated during the oxidation process (Figures 1(b) and 1(c)). The starch functionality in the elaboration of films depends on the shape and the size of the granule, a size of large granule which originates films with greater extensibility, and consequently with low resistance to deformation $[34,35]$. The distribution of starch granule size is one of the most important factors that determines many final products [36].
3.3. Content of Carbonyl and Carboxyl Groups. The content of carbonyl groups in sample A was $0.015 \%$ and $0.028 \%$ for sample B. The values of carboxyl groups increased from $0.022 \%$ (sample A) to $0.031 \%$ (sample B). Y.-J. Wang and L. Wang [19] and Garrido et al. [37] reported carboxyl contents of 0.114 and $0.44 \%$, respectively, in starches oxidized with $2 \%$ of active chlorine. There is a significant difference between findings in this study $(0.022 \%$ with $2.5 \%$ of active chlorine) and those reported by these authors. This pattern may be directly related to molecular fragmentation during the oxidative treatment [38] and the reaction conditions in which carbonyl or carboxyl groups are selectively formed by oxidation of the groups at certain positions on glycosidic rings [39]. Kuakpetoon and Wang [30] studied four types of corn starches; the common or normal (25\% amylose, $75 \%$ amylopectin), the waxy (99\% amylopectin), and high amylose (50\% and 70\%). These authors reported that the hypochlorite is consumed by the depolymerisation of the starch that contained more amylose. The oxidation was observed in high amylose starches and waxy starches, since they presented carboxyl groups. It was found that as the concentration of active chlorine increases, the content of carbonyl and carboxyl groups increases as well, presenting an increase in the carboxyl groups for the waxy starch from 0.152 to $0.162 \%$, and for the common starch from 0.046 to $0.096 \%$, at two different concentrations of $\mathrm{NaOCl}(0.8$ and $5 \%$, resp.). These results were attributed to the structural differences of starches and to the hydroxyl groups of the starch molecule that were partially oxidized to carbonyl groups. They explained that the oxidation of the starch granule is performed first in the starch amorphous lamella, that is, on the amylose domain; producing both carbonyl and carboxyl groups in the starch structure, increasing depolymerization, and favoring hydrogen bonding formation.

Y.-J. Wang and L. Wang [19] worked with two types of corn starch: the waxy and the normal one, using a level of oxidation of $0.5 \%$ of active chlorine to determine the degree of substitution of carbonyl and carboxyl groups, obtaining, as a result, $0.022 \%$ of carbonyl groups and $0.014 \%$ of carboxyl groups for the normal starch. For the concentration of $1.5 \%$ of active chlorine, they reported values for the normal starch of $0.041 \%$ of carboxyl groups and $0.040 \%$ for the waxy starch. They pointed out that the content of carboxyl groups 


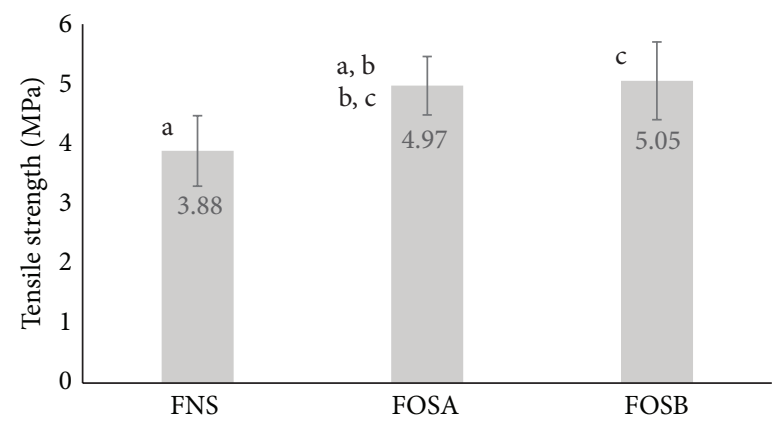

(a)

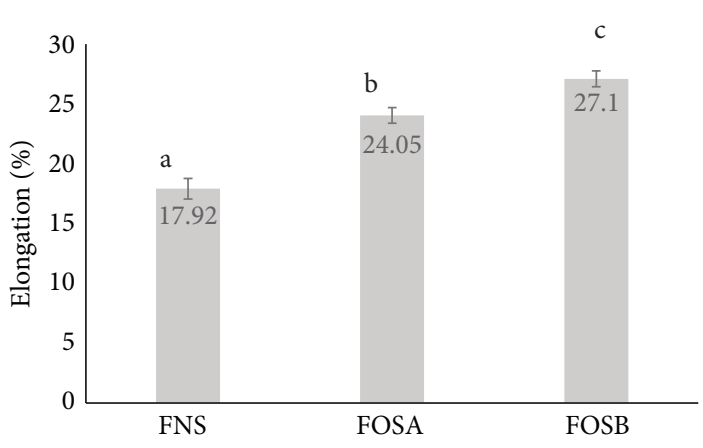

(b)

FIGURE 2: Mechanical properties of films obtained from native (FNS) and oxidized starch at 2.5\% (FOSA) and 3.5\% (FOSB) active chlorine.

increases for the normal and waxy corn starch using the different concentrations of $0.05 \%, 1.0 \%$, and $1.5 \%$ of active chlorine.

3.4. Mechanical Properties. After 30 days of storage, the mechanical properties were evaluated in the films FNS, FOSA, and FOSB, obtaining results of tensile strength (TS) and percentage of elongation $(\% E)$ presented in Figure 2. Figure 2(a) shows that the films FOSA and FOSB present a significant $(P<0.05)$ increase in the value of TS in comparison with the film FNS. This difference is attributed to zein monomers that are highly prone to associate to obtain excellent film-forming properties; thus, it would be expected that zein subunits were highly subjected to the formation of intermolecular cross-linked species [40], providing a higher structural integrity in the polymeric matrix, thereby, increasing tensile strength [41]. In fact, tensile strength is influenced by intermolecular association in the polymer matrix, which is often weakened by incorporation of a plasticizer, which works by spacing the chains of the polymer, allowing the chains to move more flexibly and thus making the plastics softer [42]. In addition, Zamudio-Flores et al. [41] also observed an increase of TS for the films elaborated with oxidized starch at $0.05 \%(\mathrm{M} 1), 1.0 \%(\mathrm{M} 2)$, and $1.5 \%$ (M3) of active chlorine, water, and glycerol, obtaining a value of $5.5 \mathrm{MPa}$ of tensile strength for the film M1, 6.85 MPa for the film M2; and 8.39 for the film M3, respectively, while, for the film from native starch, the TS was $4.66 \mathrm{MPa}$. These authors [41] concluded that the increase of tensile strength was due to the presence of carbonyl and carboxyl groups formed in the oxidation process, providing the polymer matrix with a more compact structure. Analyzing the results referred in this study in comparison with those reported by Gillgren and Stading [43], it is shown that the zein had a significant effect on the results of TS in the films, providing them with important physical features, such as an increase in flexibility and visually less brittle films than the native starch film. Another important factor, which may cause the zein used in the preparation of films, is high TS compared to other protein-based films, as reported by Ghanbarzadeh and Oromiehi [44].

Parris and Coffin [45], who elaborated films with zein, using two types of solvent, ethanol and acetone, showed a value of TS of $14.4 \mathrm{MPa}$ in films prepared with acetone, whereas the film prepared in ethanol showed a smaller value of $10.9 \mathrm{MPa}$. They concluded that the acetone forms stronger but less flexible films compared to those prepared in ethanol.

The $\% E$ in the films is also a very important characteristic, since it provides a flexibility index and shows the film capacity to absorb large amounts of energy before breaking. Figure 2(b) shows that films FNS, FOSA, and FOSB had significant differences $(P<0.05)$ over the $\% E$. Values ranged from $17.92 \pm 0.86$ to $27.10 \pm 0.66$, with higher elongations at break for samples from oxidized starch, and this may be due to the fact that, according to the oxidation method used, their hydroxyl groups were partially oxidized to aldehyde or ketone groups, enhancing their starch hydrophilicity at low concentrations, as suggested in earlier and recent works that used sodium hypochlorite $[46,47]$ and providing starch with new functionality. This phenomenon indicated the critical content of the greatest interaction of the starch polymer chain.

The increasing $\% E$ of the banana starch films with increasing concentrations of active chlorine is likely attributable to the formation of intermolecular interaction between the hydroxyl group of the amylose and amylopectin molecules and the carboxyl group of the oxidized starch [48]. On the other hand, during the processing and drying of the composite films, the original hydrogen bonds formed between starch molecules could be replaced by new hydrogen bonds, formed between the hydroxyl groups in starch molecules and the hydroxyl and carboxyl groups in the oxidized starch [49].

3.5. Water Vapour Permeability (WVP). As stated in the methods section, trying to find an equilibrium state, the WVP determination was made at 30 and 60 days of the films storage. The film FNS, at 30 days of storage, presented a WVP of $16.23 \times 10^{-11} \mathrm{~g} \mathrm{~Pa}^{-1} \mathrm{~s}^{-1} \mathrm{~m}^{-1}$, which was significantly different $(\alpha=0.05)$ from the one at 60 days of storage, of $14.35 \times 10^{-11} \mathrm{~g} \mathrm{~Pa}^{-1} \mathrm{~s}^{-1} \mathrm{~m}^{-1}$ (Figure 3). The reasons for this variation might be due to a change in structure, because of film thickness, or through a change in crystallinity, which can alter the films structure [50]. The crystalline phase is usually assumed to be impermeable. High crystalline structure may provide more dense and compact structure which contains 


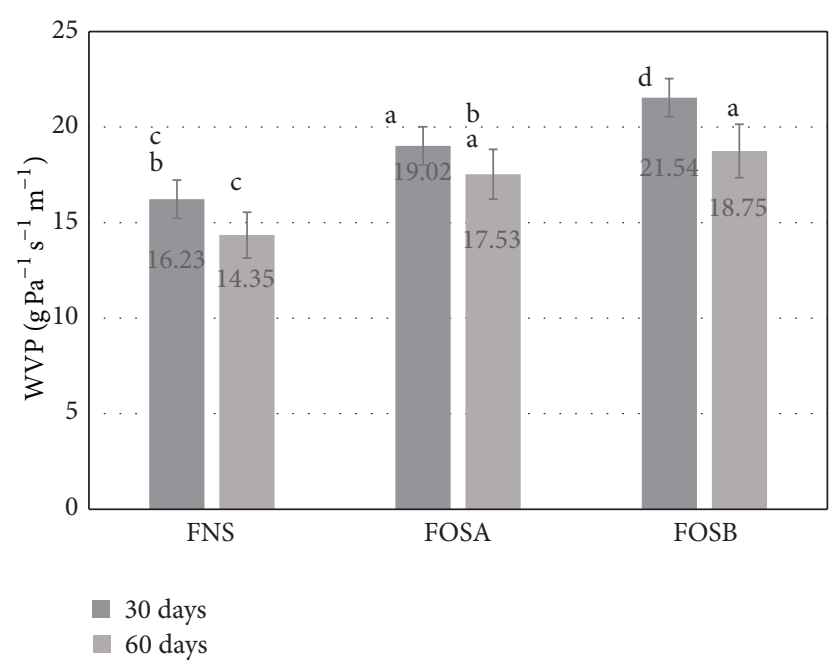

FIGURE 3: Water vapour permeability of films obtained from native (FNS) and oxidized starch at 2.5\% (FOSA) and 3.5\% (FOSB) active chlorine.

less free volume for water molecule migrations, so that WVP decreases as time passes out [51].

The value of WVP of films FOSA and FOSB increased when the gelatinized starch was oxidized, and this might be because of the already mentioned hydrophilicity of the modified starch that would increase as its hydroxyl groups were oxidized to aldehyde or ketone groups [47]. Also, glycerol addition contributed to WVP due to reduction of the film hydrophobicity, as a result of the addition of a polar compound (carbonyl group) and besides due to the fact that glycerol works as a spacer between protein chains, decreasing intermolecular forces and allowing for a greater mobility of the protein chains $[52,53]$.

The film FNS showed a WVP value of $16.23 \times$ $10^{-11} \mathrm{~g} \mathrm{~Pa}^{-1} \mathrm{~s}^{-1} \mathrm{~m}^{-1}$ in comparison with $21.54 \times$ $10^{-11} \mathrm{~g} \mathrm{~Pa}^{-1} \mathrm{~s}^{-1} \mathrm{~m}^{-1}$ for film FOSB. Values are significantly different $(\alpha=0.05)$ from those evaluated at 60 days. These values are comparable to those reported by other researches in studies carried out with films made of starch, glycerol, and zein. Zamudio-Flores et al. [41] made films with oxidized starch and glycerol, obtaining, as a result, an increase of WVP from $61.03 \times 10^{-11} \mathrm{~g} \mathrm{~Pa}^{-1} \mathrm{~s}^{-1} \mathrm{~m}^{-1}$ to $140.60^{-11} \mathrm{~g} \mathrm{~Pa}^{-1} \mathrm{~s}^{-1} \mathrm{~m}^{-1}$ for the films elaborated with oxidized starch at $0.05 \%$ and $1.5 \%$ of active chlorine; he concluded that this increase is due to the augment of active chlorine in the oxidation.

Yamada et al. [54] demonstrated that the solvent where the film is prepared can affect its WVP, observing that ethanol increases these barrier properties compared to acetone. There are also other important factors that affect (increase or decrease) the WVP of films, such as the degree of polymer crystallinity, the presence of a plasticizer during its elaboration, and the size and shape of the molecule, as well as the thickness and the presence of pores, cracks, or fractures [55].

The vapour transport through the polymer also increases, based on the relative humidity, which brings as a consequence the swelling of the material and, therefore, the permeability increases rapidly $[55,56]$.
3.6. Morphology of Films. Figure 4 shows the micrographs $(1000 \mathrm{x})$ of the surface of the films; the sample FNS shows fractures and small air bubbles, with white dots (directed by an arrow in Figure 4(a)); this can be associated with the fact that the zein was not completely dissolved, which affects and makes the surface of the film less homogenous in comparison with the FOSA, in which only small white dots are distinguished as indicated by the arrow in Figure 4(b). The film FOSB shows a smooth surface that can be associated with a greater integrity of the structure or with a greater compaction of starch; therefore, it can be said that the oxidation favored the glycerol to penetrate more easily into the granules (directed by arrows in Figure 4(c)).

In the views of cross-sectional cut (Figure 5), a few nongelatinized starch granules are observed in films NSF (directed by arrows in Figure 5(a)), in comparison with the film FOSA and FOSB (directed by arrows in Figures 5(b) and 5(c)) in which although some roughness is noticed in the film surface, nongelatinized starch granules are absent, suggesting that the oxidation process favored a more homogeneous and plasticized structure. Besides, an overall "withish" view in an oxidation level fashion is observed in films from modified starches, possibly because of a higher interaction with glycerol, being consistent with what has been mentioned above. Similar results have been found by Alanís-López et al. [57].

\section{Conclusions}

Oxidation of native banana starch was achieved with the use of sodium hypochlorite $(\mathrm{NaOCl})$ at two concentrations of active chlorine: $2.5 \%$ (FOSA) and 3.5\% (FOSB), which were used to obtain films. In their chemical composition, the oxidized starch showed differences from native starch due to the treatment to which it was subjected, and it caused elimination of lipids and proteins and a decrease in apparent amylose, which might well be the main oxidation target. The addition of glycerol and the increasing level of oxidation increased the films moisture.

Films, made with oxidized starch, showed improved tensile properties and fracture elongation percentage, with respect to those of the native starch. The amount of zein used caused a decrease in these mechanical properties, as well as a significant decrease in water vapour permeability. Films from FOSA and FOSB showed higher permeability than that of the native starch. It was observed in the micrographs that, during the oxidation process, impurities were largely eliminated from the starch granule, noting more homogeneous structure in oxidized specimens.

\section{Conflict of Interests}

The authors declare that there is no conflict of interests regarding the publication of this paper. 


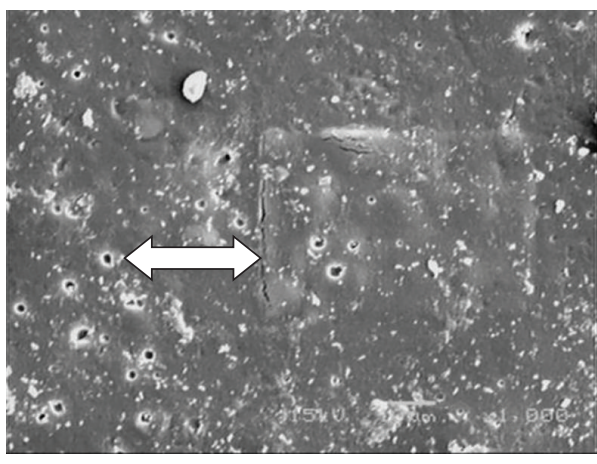

(a)

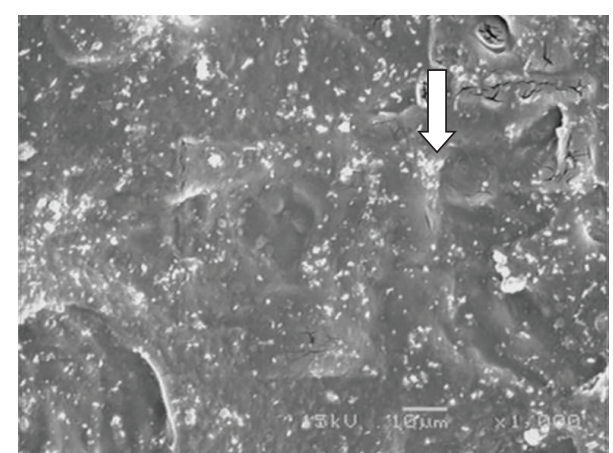

(b)

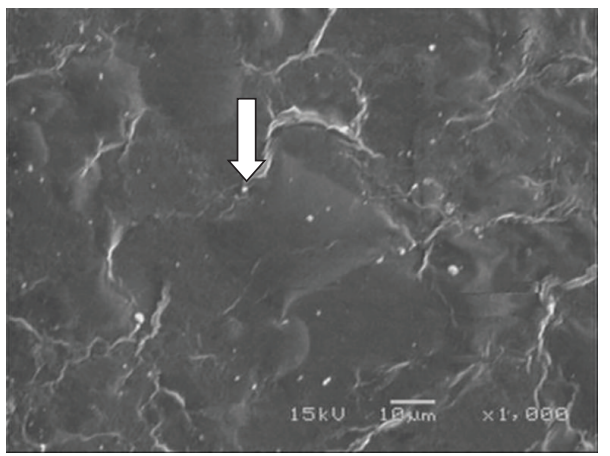

(c)

FIGURE 4: SEM micrographs (1000X) of the surface of the films; FNS (a), FOSA (b), and FOSB (c) (scale bar: $10.0 \mu \mathrm{m}$ ).

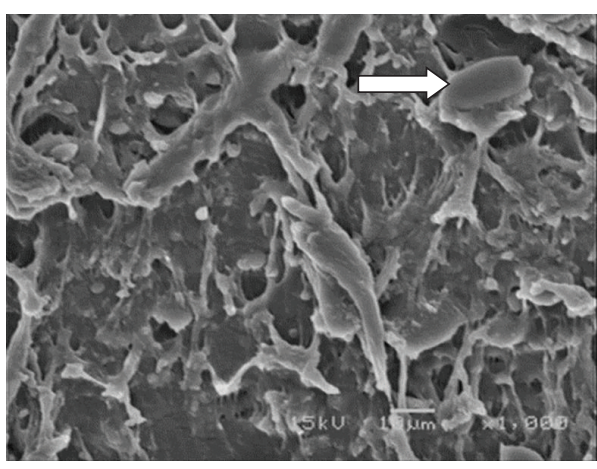

(a)

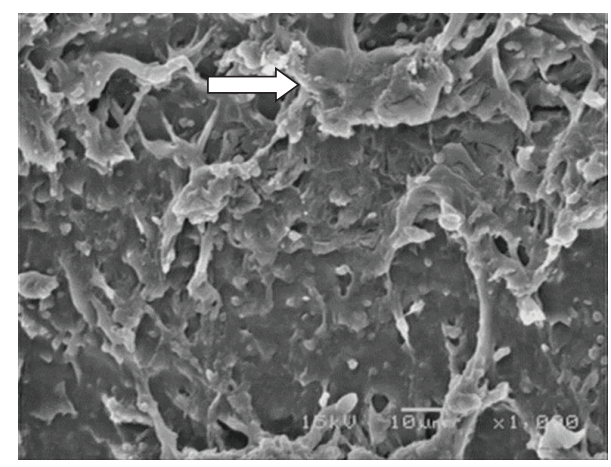

(b)

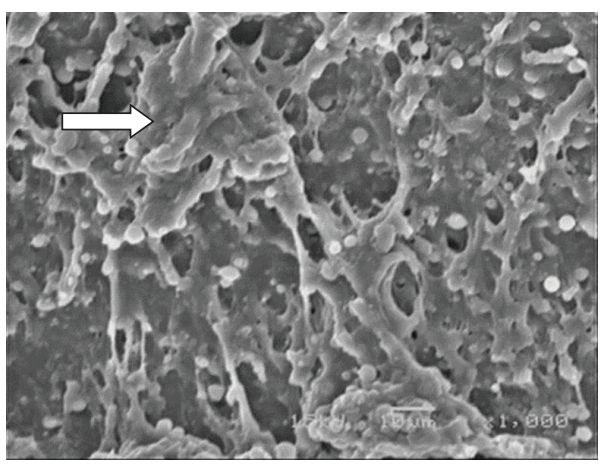

(c)

FIGURE 5: SEM micrographs (1000X) of views of cross-sectional cut of the films; FNS (a), FOSA (b), and FOSB (c) (scale bar: $10.0 \mu \mathrm{m})$. 


\section{Acknowledgments}

The financial support from Instituto Politécnico NacionalSIP, Project: 20131083 in Mexico, is fully acknowledged. Thanks are also due to CONACyT for financial support (Project: 60565-Z).

\section{References}

[1] D. A. Silva, R. C. M. De Paula, J. P. A. Feitosa, A. C. F. De Brito, J. S. Maciel, and H. C. B. Paula, "Carboxymethylation of cashew tree exudate polysaccharide," Carbohydrate Polymers, vol. 58, no. 2, pp. 163-171, 2004.

[2] Z. Chen, L. Zhang, and L. Wang, "Study on filming of oxidized starch/PVA," Frontiers of Agriculture in China, vol. 5, no. 4, pp. 649-654, 2011.

[3] I. Vroman and L. Tighzert, "Biodegradable polymer," Materials, vol. 2, no. 2, pp. 307-344, 2009.

[4] Y. Wang, L. Jiang, J. Duan, and S. Shao, "Effect of the carbonyl content on the properties of composite films based on oxidized starch and gelatin," Journal of Applied Polymer Science, vol. 130, no. 4, pp. 2753-2763, 2013.

[5] S. Galus, A. Lenart, A. Voilley, and F. Debeaufort, "Effect of oxidized potato starch on the physicochemical properties of soy protein isolate-based edible films," Food Technology and Biotechnology, vol. 5, no. 3, pp. 403-409, 2013.

[6] E. D. R. Zavareze, V. Z. Pinto, B. Klein et al., "Development of oxidised and heat-moisture treated potato starch film," Food Chemistry, vol. 132, no. 1, pp. 344-350, 2012.

[7] L. Yiang and J. Zhang, "Biodegradable polymers and polymer blends," in Handbook of Biopolymers and Biodegradable Plastics, pp. 109-128, Elsevier, Whaltam, Mass, USA, 2013.

[8] F. Parvin, M. A. Rahman, J. M. M. Islam, M. A. Khan, and A. H. M. Saadat, "Preparation and characterization of starch/PVA blend for biodegradable packaging material," Advanced Materials Research, vol. 123-125, pp. 351-354, 2010.

[9] H. Röper, "Renewable raw materials in Europa-industrial utilisation of starch and sugar," Starch/Stärke, vol. 54, no. 3-4, pp. 89-99, 2002.

[10] J. Preiss, Starch in Food: Structure, Function and Applications, CRC Press, New York, NY, USA, 2004.

[11] R. F. Tester, J. Karkalas, and X. Qi, "Starch-composition, fine structure and architecture," Journal of Cereal Science, vol. 39, no. 2, pp. 151-165, 2004.

[12] F. Xie, L. Yu, B. Su et al., "Rheological properties of starches with different amylose/amylopectin ratios," Journal of Cereal Science, vol. 49, no. 3, pp. 371-377, 2009.

[13] W. S. Ratnayake, R. Hoover, and T. Warkentin, "Pea starch: composition, structure and properties-a review," Starch/Stärke, vol. 54, no. 6, pp. 217-234, 2002.

[14] P. Zhang, R. L. Whistler, J. N. Bemiller, and B. R. Hamaker, "Banana starch: production, physicochemical properties, and digestibility-a review," Carbohydrate Polymers, vol. 59, no. 4, pp. 443-458, 2005.

[15] K. Sangseethong, N. Termvejsayanon, and K. Sriroth, "Characterization of physicochemical properties of hypochlorite- and peroxide-oxidized cassava starches," Carbohydrate Polymers, vol. 82, no. 2, pp. 446-453, 2010.

[16] D. Kuakpetoon and Y. Wang, "Characterization of different starches oxidized by hypochlorite," Starch/Stärke, vol. 53, no. 5, pp. 211-218, 2001.
[17] G. Hu, J. Chen, and J. Gao, "Preparation and characteristics of oxidized potato starch films," Carbohydrate Polymers, vol. 76, no. 2, pp. 291-298, 2009.

[18] S. Pietrzyk and T. Fortuna, "Oxidation induced changes in the surface structure in the starch granule," Polish Journal of Food Nutrition Science, vol. 14, no. 55, pp. 159-164, 2005.

[19] Y.-J. Wang and L. Wang, "Physicochemical properties of common and waxy corn starches oxidized by different levels of sodium hypochlorite," Carbohydrate Polymers, vol. 52, no. 3, pp. 207-217, 2003.

[20] R. Shukla and M. Cheryan, "Zein: the industrial protein from corn," Industrial Crops and Products, vol. 13, no. 3, pp. 171-192, 2001.

[21] I. Goñi and C. Valentín-Gamazo, "Chickpea flour ingredient slows glycemic response to pasta in healthy volunteers," Food Chemistry, vol. 81, no. 4, pp. 511-515, 2003.

[22] R. Hoover and W. S. Ratnayake, "Starch characteristics of black bean, chick pea, lentil, navy bean and pinto bean cultivars grown in Canada," Food Chemistry, vol. 78, no. 4, pp. 489-498, 2002.

[23] P. Kampeerapappun, D. Aht-ong, D. Pentrakoon, and K. Srikulkit, "Preparation of cassava starch/montmorillonite composite film," Carbohydrate Polymers, vol. 67, no. 2, pp. 155-163, 2007.

[24] S. Chattopadhyay, R. S. Singhal, and P. R. Kulkarni, “Optimisation of conditions of synthesis of oxidised starch from corn and amaranth for use in film-forming applications," Carbohydrate Polymers, vol. 34, no. 4, pp. 203-212, 1998.

[25] S. Mali, M. V. E. Grossmann, M. A. Garcia, M. N. Martino, and N. E. Zaritzky, "Microstructural characterization of yam starch films," Carbohydrate Polymers, vol. 50, no. 4, pp. 379-386, 2002.

[26] ASTM 882-09, Standard Test Method for Tensile Properties of Thin Plastic Sheeting, American Society for Testing and Materials, West Conshohocken, Pa, USA, 2009.

[27] ASTM E96-95, Standard Test Methods for Water Vapour Transmission of Materials in Sheet Form, American Society for Testing and Materials, West Conshohocken, Pa, USA, 1995.

[28] Y. V. García-Tejeda, C. López-González, J. P. Pérez-Orozco et al., "Effect of storage on the mechanical and physicochemical properties of extruded laminates from native and oxidized banana (Musa paradisiaca L.) Starch," LWT-Food Science and Technology, vol. 54, no. 2, pp. 1-9, 2013.

[29] R. Jiménez-Vera, N. González-Cortés, A. Magaña-Contreras, and A. I. Corona-Cruz, "Contenido de almidon resistente en alimentos consumidos en el sureste de Mexico," Unacar Tecnociencia, vol. 5, no. 2, pp. 27-34, 2011.

[30] D. Kuakpetoon and Y.-J. Wang, "Structural characteristics and physicochemical properties of oxidized corn starches varying in amylose content," Carbohydrate Research, vol. 341, no. 11, pp. 1896-1915, 2006.

[31] E. Bertoft, "Lintnerization of two amylose-free starches of Aand B-crystalline types, respectively," Starch/Stärke, vol. 56, no. 5, pp. 167-180, 2004.

[32] J. Singh and N. Singh, "Studies on the morphological and rheological properties of granular cold water soluble corn and potato starches," Food Hydrocolloids, vol. 17, no. 1, pp. 63-72, 2003.

[33] R. F. Tester and J. Karkalas, Polysaccharides II: Polysaccharides from Eukaryotes, Wiley-VCH, Weinheim, Germany, 2004. 
[34] Z.-Q. Fu, L.-J. Wang, D. Li, Q. Wei, and B. Adhikari, "Effects of high-pressure homogenization on the properties of starchplasticizer dispersions and their films," Carbohydrate Polymers, vol. 86, no. 1, pp. 202-207, 2011.

[35] S.-T. Lim, "Effect of starch granule size on physical properties of starch-filled polyethylene film," Biotechnology Progress, vol. 8, no. 1, pp. 51-57, 1992.

[36] S.-H. Park, J. D. Wilson, and B. W. Seabourn, "Starch granule size distribution of hard red winter and hard red spring wheat: its effects on mixing and breadmaking quality," Journal of Cereal Science, vol. 49, no. 1, pp. 98-105, 2009.

[37] L. H. Garrido, E. Schnitzler, M. E. Boff Zortéa, and T. de Souza Rocha I Mottin Demiate, "Physicochemical properties of cassava starch oxidized by sodium hypoclorite," Journal of Food Science and Technology, 2012.

[38] S. Richardson and L. Gorton, "Characterisation of the substituent distribution in starch and cellulose derivatives," Analytica Chimica Acta, vol. 497, no. 1-2, pp. 27-65, 2003.

[39] P. L. Bragd, A. C. Besemer, and H. Van Bekkum, "Bromidefree TEMPO-mediated oxidation of primary alcohol groups in starch and methyl $\alpha$-D-glucopyranoside," Carbohydrate Research, vol. 328, no. 3, pp. 355-363, 2000.

[40] C. Mu-Forster and B. P. Wasserman, "Surface localization of zein storage proteins in starch granules from maize endosperm: proteolytic removal by thermolysin and in vitro cross-linking of granule-associated polypeptides," Plant Physiology, vol. 116, no. 4, pp. 1563-1571, 1998.

[41] P. B. Zamudio-Flores, A. Vargas-Torres, J. Pérez-González, E. Bosquez-Molina, and L. A. Bello-Pérez, "Films prepared with oxidized banana starch: mechanical and barrier properties," Starch/Stärke, vol. 58, no. 6, pp. 274-282, 2006.

[42] K. Shi, H. Yu, S. L. Rao, and T. C. Lee, "Improved mechanical property and water resistance of zein films by plasticization with tributyl citrate," Journal of Agricultural and Food Chemistry, vol. 60, pp. 5988-5993, 2012.

[43] T. Gillgren and M. Stading, "Mechanical and barrier properties of avenin, kafirin, and zein films," Food Biophysics, vol. 3, no. 3, pp. 287-294, 2008.

[44] B. Ghanbarzadeh and A. R. Oromiehi, "Biodegradable biocomposite films based on whey protein and zein: barrier, mechanical properties and AFM analysis," International Journal of Biological Macromolecules, vol. 43, no. 2, pp. 209-215, 2008.

[45] N. Parris and D. R. Coffin, "Composition factors affecting the water vapor permeability and tensile properties of hydrophilic zein films," Journal of Agricultural and Food Chemistry, vol. 45, no. 5, pp. 1596-1599, 1997.

[46] R. E. Wing and J. L. Willett, "Water soluble oxidized starches by peroxide reactive extrusion," Industrial Crops and Products, vol. 7, no. 1, pp. 45-52, 1997.

[47] X. Yi, S. Zhang, and B. Ju, "Preparation of water-soluble oxidized starch with high carbonyl content by sodium hypochlorite," Starch/Stärke, vol. 65, pp. 1-9, 2013.

[48] Y. Li, C. F. Shoemaker, J. Ma, X. Shen, and F. Zhong, "Paste viscosity of rice starches of different amylose content and carboxymethylcellulose formed by dry heating and the physical properties of their films," Food Chemistry, vol. 109, no. 3, pp. 616-623, 2008.

[49] X. Ma, P. R. Chang, and J. Yu, "Properties of biodegradable thermoplastic pea starch/carboxymethyl cellulose and pea starch/microcrystalline cellulose composites," Carbohydrate Polymers, vol. 72, no. 3, pp. 369-375, 2008.
[50] L. Z. Wang, L. Liu, J. Holmes, J. F. Kerry, and J. P. Kerry, “Assessment of film-forming potential and properties of protein and polysaccharide-based biopolymer films," International Journal of Food Science and Technology, vol. 42, no. 9, pp. 1128-1138, 2007.

[51] K. S. Miller and J. M. Krochta, "Oxygen and aroma barrier properties of edible films: a review," Trends in Food Science and Technology, vol. 8, no. 7, pp. 228-237, 1997.

[52] Y.-R. Zhang, S.-D. Zhang, X.-L. Wang, R.-Y. Chen, and Y.Z. Wang, "Effect of carbonyl content on theproperties of thermoplastic oxidized starch," Carbohydrate Polymers, vol. 78, no. 1, pp. 157-161, 2009.

[53] F. Tihminlioglu, I. D. Atik, and B. Özen, "Water vapor and oxygen-barrier performance of corn-zein coated polypropylene films," Journal of Food Engineering, vol. 96, no. 3, pp. 342-347, 2010.

[54] K. Yamada, H. Takahahi, and A. Noguchi, "Improved water resistance in edible zein films and composites for biodegradable food packaging," International Journal of Food Science \& Technology, vol. 30, no. 5, pp. 599-608, 1995.

[55] M. Karel and D. B. Lund, Physical Principles of Food Preservation, Marcel Dekker, New York, NY, USA, 2003.

[56] M. A. Del Nobile and A. Conte, Packaging for Food Preservation, Springer, Berlin, Germany, 2013.

[57] P. Alanís-López, J. Pérez-González, R. Rendón-Villalobos, A. Jiménez-Pérez, and J. Solorza-Feria, "Extrusion and characterization of thermoplastic starch sheets from "Macho" banana," Journal of Food Science, vol. 76, no. 6, pp. E465-E471, 2011. 

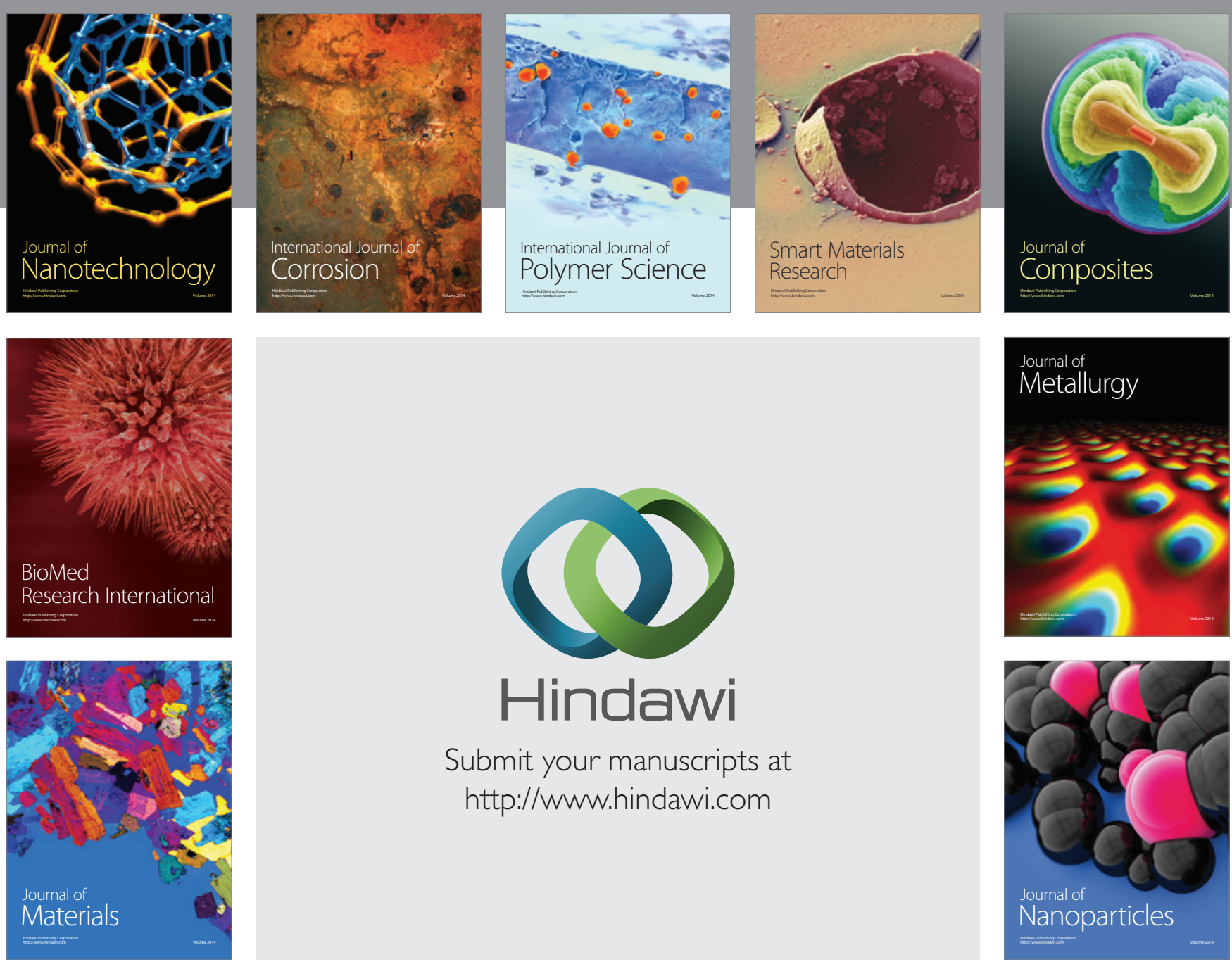

Submit your manuscripts at http://www.hindawi.com
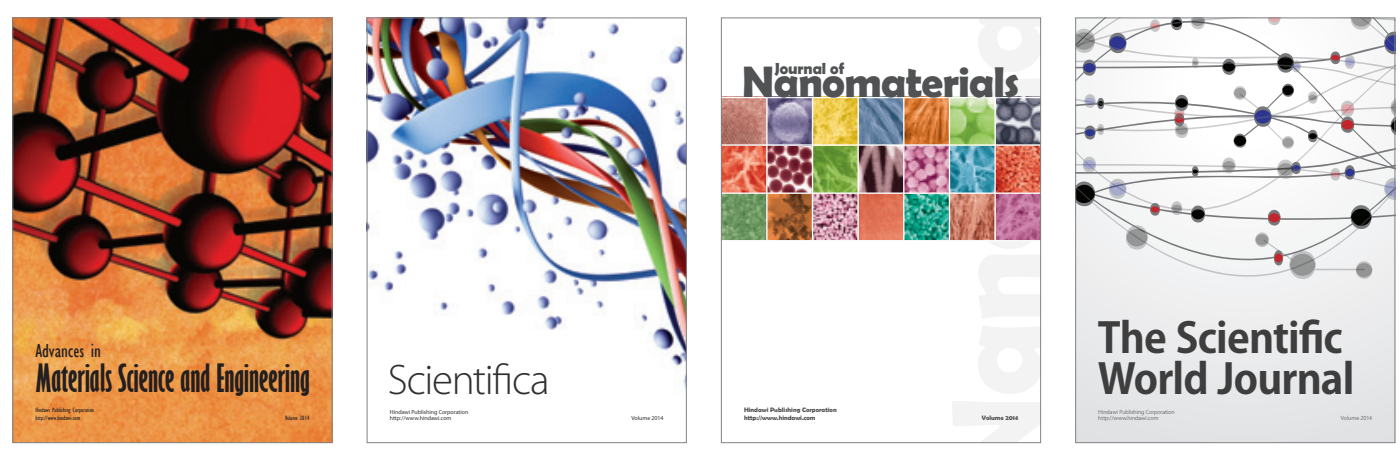

\section{The Scientific World Journal}
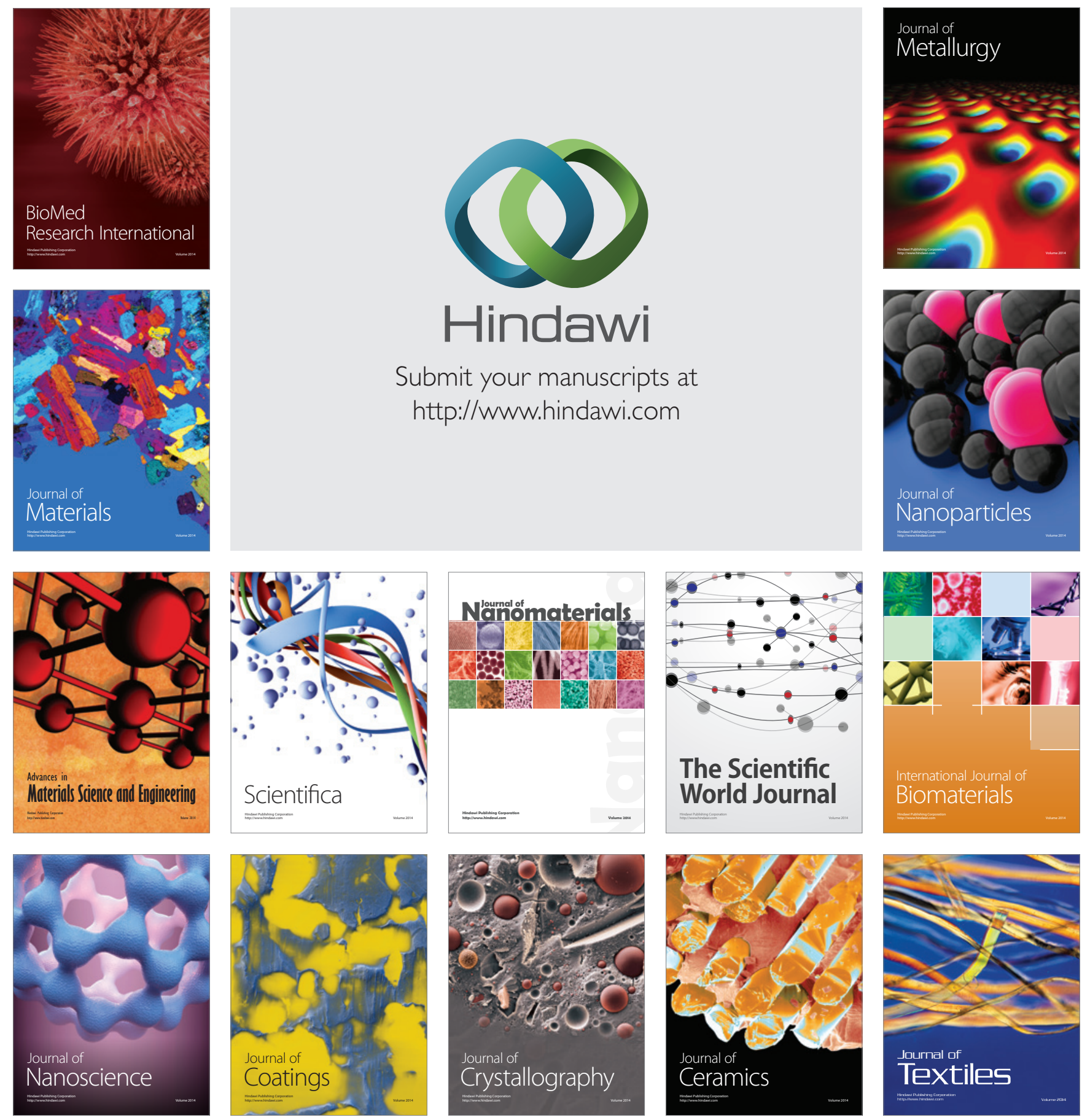